\title{
Evaluation of the efficacy of ivermectin against Theileria orientalis infection in grazing cattle
}

\author{
Jinho Park ${ }^{1 \dagger}$, Jeong-Byoung Chae ${ }^{2 \dagger}$, Suhee $\mathrm{Kim}^{3}$, Do-Hyeon Yu${ }^{4}$, Hyeon-Cheol Kim5, Bae-Keun Park ${ }^{6}$, \\ Joon-Seok Chae ${ }^{2}$ and Kyoung-Seong $\mathrm{Choi}^{7^{*}}$ (D)
}

\begin{abstract}
Background: Raising cattle on pastures is known to be beneficial for animal welfare and cost reduction. However, grazing is associated with the risk of contracting tick-borne diseases, such as theileriosis. Here, the efficacy of ivermectin against these diseases and associated clinical symptoms were evaluated.

Results: A total of 68 cattle from a grazing cattle farm were selected and divided into two groups: the control group (17 cattle) with no preventive treatment and the ivermectin-treated group (51 cattle) in which cattle were treated with pour-on ivermectin prior to grazing. The infection rates of Theileria orientalis and the red blood cell (RBC) profile (e.g., RBC count, hematocrit value, and hemoglobin concentration) were compared in the spring (before grazing) and summer (during grazing) between the two groups. Based on PCR amplification of the major piroplasm surface protein (MPSP) gene, 12 cattle were positive for $T$. orientalis infection. Phylogenetic analysis revealed that the isolates identified in this study consisted of three MPSP types (1,2, and 7). The T. orientalis infection rate in the control group during grazing was 3 -fold higher than that in the ivermectin-treated group. Moreover, differences in RBC parameters during grazing were greater in the control group than in the ivermectintreated group. In particular, the hematocrit value was significantly reduced in the control group.

Conclusions: The results of this study demonstrated that ivermectin had protective effects against T. orientalis infection and RBC hemolysis in grazing cattle.
\end{abstract}

Keywords: Grazing, Hematocrit, Ivermectin, Theileria orientalis

\section{Background}

Theileria orientalis is a tick-borne hemoprotozoan parasite that can cause clinical disease and lead to significant economic losses in the livestock industry in the Asia-Pacific region through anemia, jaundice, growth retardation, and reduced body weight in cattle [1-3]. T. orientalis is transmitted to the host through blood-sucking infected hard ticks [4]. One of the vectors of T. orientalis is Haemaphysalis longicornis, which is the most commonly found tick in the Republic of Korea (ROK) [5, 6]. Anemia and abortion are common clinical outcomes of this disease $[7,8]$. The importance of controlling $T$. orientalis infection has

\footnotetext{
* Correspondence: kschoi3@knu.ac.kr

†Jinho Park and Jeong-Byoung Chae contributed equally to this work.

${ }^{7}$ College of Ecology and Environmental Science, Kyungpook National

University, Sangju 37224, South Korea

Full list of author information is available at the end of the article
}

been highlighted by recent outbreaks reported in Australia and New Zealand [1,9]. Recently, the prevalence of $T$. orientalis infection has gradually increased in the ROK, and several genotypes $T$. orientalis have been reported [10]. However, no effective drugs or vaccines are currently available for controlling $T$. orientalis.

In comparison with conventional indoor housing, raising cattle on pastures is known to be beneficial for the health of animals and has many other advantages, including greater cattle activity, improvements in productivity, good animal welfare, and reduction in rearing costs and workloads $[11,12]$. However, raising cattle on pastures may also have disadvantages, such as the risk of being bitten by ticks and developing infections through tick-borne pathogens with related clinical symptoms [13]. To prevent ticks and tick-borne diseases while maintaining the advantages of

(c) The Author(s). 2019 Open Access This article is distributed under the terms of the Creative Commons Attribution 4.0 International License (http://creativecommons.org/licenses/by/4.0/), which permits unrestricted use, distribution, and reproduction in any medium, provided you give appropriate credit to the original author(s) and the source, provide a link to the Creative Commons license, and indicate if changes were made. The Creative Commons Public Domain Dedication waiver (http://creativecommons.org/publicdomain/zero/1.0/) applies to the data made available in this article, unless otherwise stated. 
pasturing, several methods to control ticks and tick-borne pathogens have been developed and evaluated [14, 15]. Recently, the number of cattle grazing on pastures in the ROK has increased. Although many studies have investigated treatment approaches to prevent the infestation of ticks or methods that focus on the detection of pathogens after the application of anti-ectoparasitic chemicals, little is known about the effects of controlling tick-borne pathogens and related clinical symptoms in the host.

Among the various anti-ectoparasitic chemicals reported thus far, ivermectin is a useful drug for the management of grazing cattle $[14,16]$, and it is a well-known repellent for various ticks [17-20]. However, its effects on H. longicornis have not been evaluated. Therefore, the aim of this study was to evaluate the efficacy of ivermectin against $T$. orientalis infection and red blood cell (RBC) hemolysis by administration to cattle before grazing. This study may contribute to the development of control measures for bovine theileriosis.

\section{Results}

Of the tick-borne pathogens examined, only $T$. orientalis was detected in 12 cattle, and other tick-borne pathogens were not found in these cattle. These $T$. orientalis-positive cattle did not exhibit clinical symptoms, such as anorexia, depression, and reduced milk production. Based on the sequencing of all 12 amplicons, 8 good sequences were obtained and classified into three genotypes (4 sequences for type 1, 2 sequences for type 2 , and 2 sequences for type 7 ) by phylogenetic analysis (Fig. 1). Four isolates, which belonged to type 1 (Chitose), showed $99.8-100 \%$ identity to each other, and these isolates were closely related to a Korean isolate (JN648690). Two isolates, which belonged to type 2 (Ikeda), showed 99.5-99.7\% homology to a Korean isolate (KY018574) previously reported by our group. The nucleotide sequence similarity of the two isolates belonging to type 7 was $93.5 \%$ and these isolates formed the same clade with a Japanese isolate (AB218430) and a Chinese isolate (FJ560987) (Fig. 1). There was no mixture of genotypes in this herd.

To evaluate the efficacy of ivermectin, the infection rate of $T$. orientalis was compared between the control and ivermectin-treated groups. As shown in Fig. 2, in the control group, the infection rate of T. orientalis was 5.9\% (1/ 17 ) in the spring (before grazing) and $23.5 \%(4 / 17)$ in the summer (during grazing). In contrast, in the ivermectintreated group, the infection rate of $T$. orientalis was 5.9\% $(3 / 51)$ in the spring and $7.8 \%(4 / 51)$ in the summer. The infection rate of $T$. orientalis in both the control and ivermectin-treated groups during grazing was increased by 3.9-fold (23.5/5.9) and 1.3-fold (7.8/5.9), respectively, compared with the rate before grazing (Fig. 2). T. orientalis infection in the control group was increased by 3 -fold compared with that in the ivermectin-treated group in the summer.

Differences in blood test results from spring to summer between the control and ivermectin-treated groups were compared (Table 1). Seasonal differences in the RBC count $(\mathrm{M} / \mu \mathrm{L})$ and $\mathrm{Hb}$ concentration $(\mathrm{g} / \mathrm{dL})$ were lower in the control group than in the ivermectin-treated group; however, these results were not statistically significant. The average $\mathrm{RBC}$ count $(\mathrm{M} / \mu \mathrm{L})$, Hct value (\%), and $\mathrm{Hb}$ concentration $(\mathrm{g} / \mathrm{dL})$ in the ivermectin-treated group were significantly decreased $(p<0.01)$ in the summer (Table 1$)$. The largest difference was observed for the Hct value. In the control group, the Hct value was $34.4 \%$ in the spring and was reduced to $30.9 \%$ in the summer $(10.2 \%$ reduction); in contrast, in the ivermectin-treated group, the Hct value was $31.9 \%$ before grazing and was decreased to $30.2 \%$ during grazing (5.3\% reduction). The average difference in the Hct value (\%) from spring to summer was significantly smaller $(p<0.01)$ in the control group than in the ivermectin-treated group (Fig. 3).

\section{Discussion}

The occurrence of tick-borne diseases may have adverse effects in cattle, necessitating the development of methods to prevent these diseases in grazing cattle. In the present study, the efficacy of ivermectin in controlling $T$. orientalis infection and associated hematological findings were evaluated. Significant differences in $T$. orientalis infection and the RBC profile were observed between the control and ivermectin-treated groups when comparing the values before and after grazing. The results of this study showed that ivermectin was effective against $T$. orientalis infection and RBC hemolysis.

T. orientalis consists of 11 MPSP genotypes, including types $1-8$ and $\mathrm{N}-1$ to $\mathrm{N}-3$ [10]. Phylogenetic analysis based on the MPSP sequences revealed the presence of three genotypes (types 1, 2, and 7). Of the three MPSP genotypes identified in this study, type 1 was detected most frequently on this farm. However, this finding is inconsistent with a previous study by our group showing that type 2 was the most common type in cattle in the ROK [10]. This suggests potential differences in the regional distribution of $T$. orientalis. The MPSP sequences of the three $T$. orientalis genotypes identified in this study were closely related to those previously identified in the ROK and Japan. Based on genotypic differences, type 2 was closely related to type 7 and was different from type 1 (Fig. 1). There is no report of type 7 in cattle in the ROK; thus, it is difficult to compare genetic differences. Nevertheless, the results showed genetic variations within type 2 in the ROK compared with type 1. Further studies are needed to investigate the association between each type and clinical signs. 


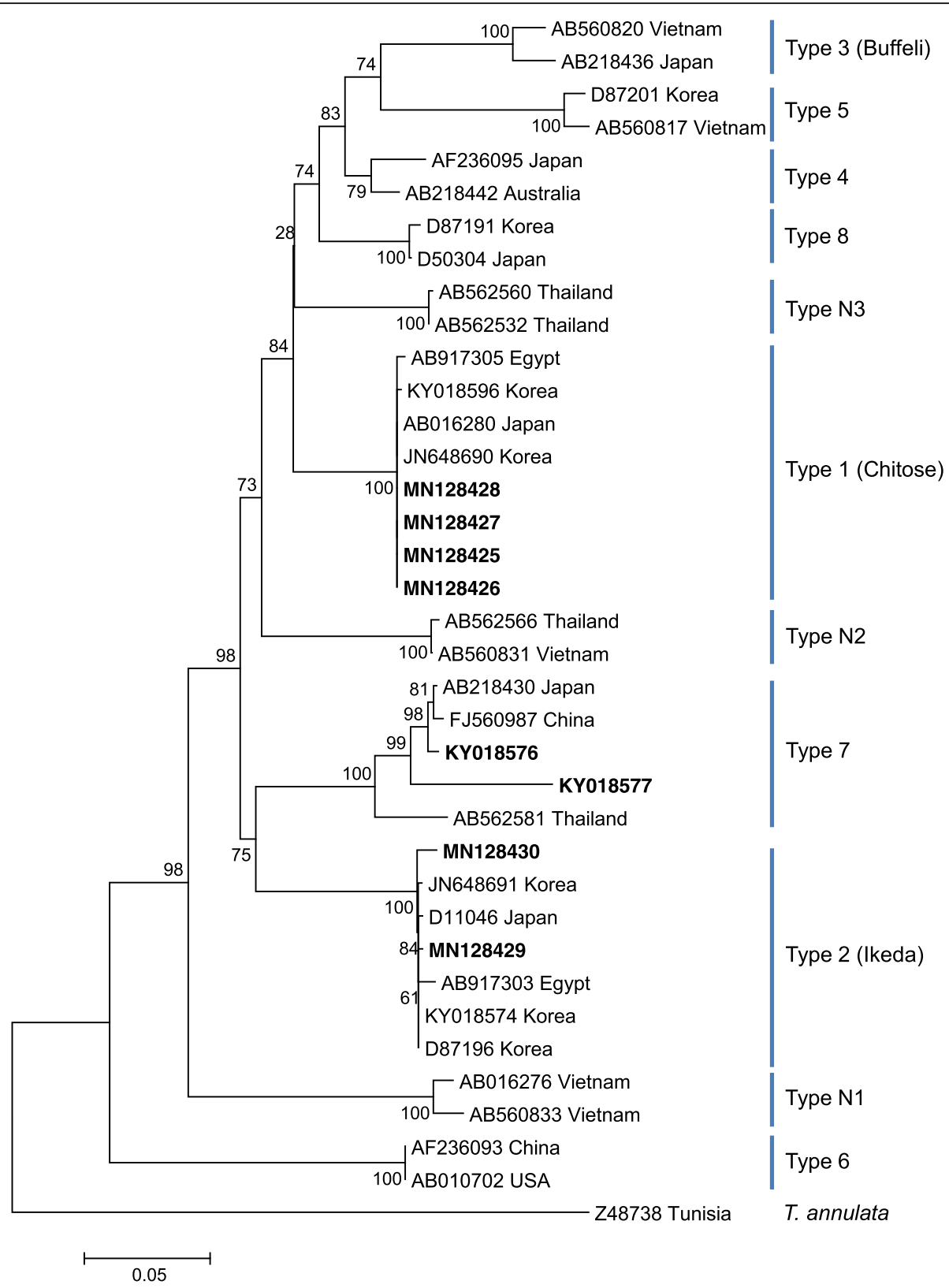

Fig. 1 Phylogenetic analysis of Theileria orientalis based on the MPSP gene. A phylogenetic tree was constructed using MEGA7 software and the maximum likelihood method; numbers over branches indicate the bootstrap values in percentages (1000 replicates) that support each phylogenetic branch. The bold-faced type indicates sequences determined in this study

In this study, tick infestation in cattle after ivermectin administration was not specifically evaluated because some ticks have been removed by the farm manager. This may be explained the lack of blood-sucking ticks on the cattle at the time of blood collection. The ticks examined on the grassland around the pasture were $H$. longicornis, which was the only species of ticks found in this study. We cannot make a definite conclusion about the effectiveness of ivermectin for tick infestation; however, it may potentially reduce the number of ticks.
According to the results of the current study, the infection rate of $T$. orientalis was increased in both the control and ivermectin-treated groups during grazing; however, the increase in the infection rate was slightly lower in the ivermectin-treated group. In this study, ivermectin was used as a pour-on formulation for the cattle and not as an injection prior to grazing. This may explain the observed T. orientalis infection in this group. The mechanism of action of ivermectin appears to vary among organisms. Ivermectin inhibits signal transmission at the neuromuscular 


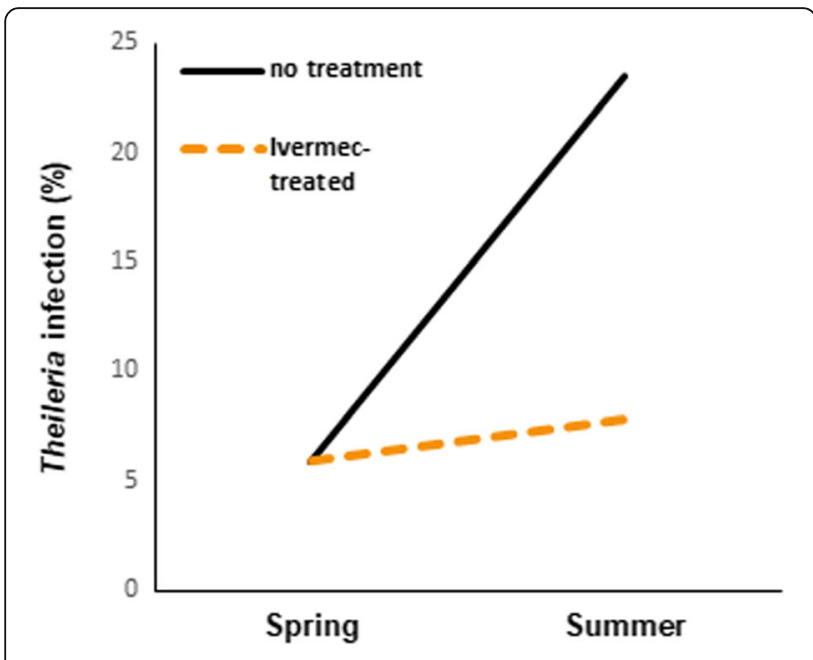

Fig. 2 Comparison of the infection rates of Theileria orientalis between the control and ivermectin-treated groups in the spring and summer

junction of some arthropods by stimulating the release of the inhibitory neurotransmitter $\gamma$-aminobutyric acid from presynaptic nerve terminals [21]. Moreover, ivermectin suppresses the engorgement, moulting, and reproduction of various ticks, such as Amblyomma hebraeum, Boophilus microplus, and Ixodid ticks [22]. However, the effects of ivermectin have not been evaluated for $H$. longicornis, which is the most prevalent tick in the ROK. In this study, the infection rate of $T$. orientalis was 3 times higher in the control group than in the ivermectin-treated group. The results of this study indicated that ivermectin had protective effects against $T$. orientalis infection. Therefore, further studies are needed to compare $T$. orientalis infection rates in grazing cattle after treatment with ivermectin at different doses using different methods of application (pour or injection).

In this study, RBC parameters (RBC count, Hct value, and $\mathrm{Hb}$ concentration) were decreased during grazing in both the control and ivermectin-treated groups, which is consistent with the findings of a previous study [13]. Tick biting may occur during the grazing of cattle, which could result in the transmission of tick-borne diseases via hemoparasites and subsequent hemolysis. Interestingly, the difference in Hct values was the greatest, with a 2-fold reduction in the control group compared with the ivermectin-treated group, indicating that ivermectin had protective effects against hemolysis in cattle during grazing. Although the mechanisms by which ivermectin affects only Hct were not evaluated in the current study, a previous study showed that ivermectin restored reduced Hct levels to normal levels in experimentally infected lambs with Haemonchus contortus [23]. This may be associated with indirect protection against ectoparasites considering that the vectors of several hemoparasites can cause hemolysis in the host [13, 24]. Ivermectin is a semi-synthetic anti-parasitic drug that is used to control intestinal nematodes and ticks that affect cattle $[16,21,23,25]$. Ivermectin is highly effective for treating endoparasite infection; however, its effects on ectoparasites in cattle are unknown. The results of this study indicated that ivermectin might be effective for preventing RBC hemolysis caused by hemoparasites. Therefore, ivermectin could be used as an anti-ectoparasitic agent. Further studies are required to assess the effects of ivermectin on other blood parameters in host animals.

\section{Conclusion}

In this study, ivermectin was found to be effective for controlling T. orientalis infection and RBC hemolysis in grazing cattle. Ivermectin could prevent tick-borne diseases and related clinical symptoms, thus reducing the disadvantages associated with raising cattle on pastures.

\section{Methods}

Ethics statement

All animal procedures were carried out according to ethical guidelines for the use of animal samples, as approved by Chonbuk National University (Institutional Animal Care and Use Committee Decision No. CBU 2016-00026). All procedures and possible consequences were explained to the managers of the surveyed farm, and written consent was obtained.

Table 1 Hematological results of the control and ivermectin-treated groups

\begin{tabular}{lllll}
\hline Group & Season & RBC (M/uL) $(5.0-10.0)^{\mathrm{a}}$ & Hct (\%) (28.0-38.0 $)^{\mathrm{a}}$ & $\mathrm{Hb}(\mathrm{g} / \mathrm{dL})(9.0-14.0)^{\mathrm{a}}$ \\
\hline Control group & Spring & $8.9 \pm 0.1$ & $34.4 \pm 0.5$ & $11.7 \pm 0.2$ \\
& Summer & $7.9 \pm 0.2$ & $30.9 \pm 0.6$ & $11.0 \pm 0.2$ \\
& Difference & $1.0 \pm 0.1^{* *}$ & $3.5 \pm 0.4^{* *}$ & $0.8 \pm 0.1$ \\
Ivermectin-treated group & Spring & $8.6 \pm 0.1$ & $31.9 \pm 0.4$ & $11.4 \pm 0.1$ \\
& Summer & $7.8 \pm 0.1$ & $30.2 \pm 0.3$ & $10.7 \pm 0.1$ \\
& Difference & $0.8 \pm 0.1^{* *}$ & $1.8 \pm 0.3^{* *}$ & $0.7 \pm 0.1^{* *}$ \\
\hline
\end{tabular}

The difference represents the subtraction of summer results from spring results

Data are presented as the mean \pm SEM. $P$ values were obtained by Shapiro-Wilk test $\left({ }^{*} P<0.05\right.$ and $\left.{ }^{* *} P<0.01\right)$

${ }^{\text {a }}$ The reference range 


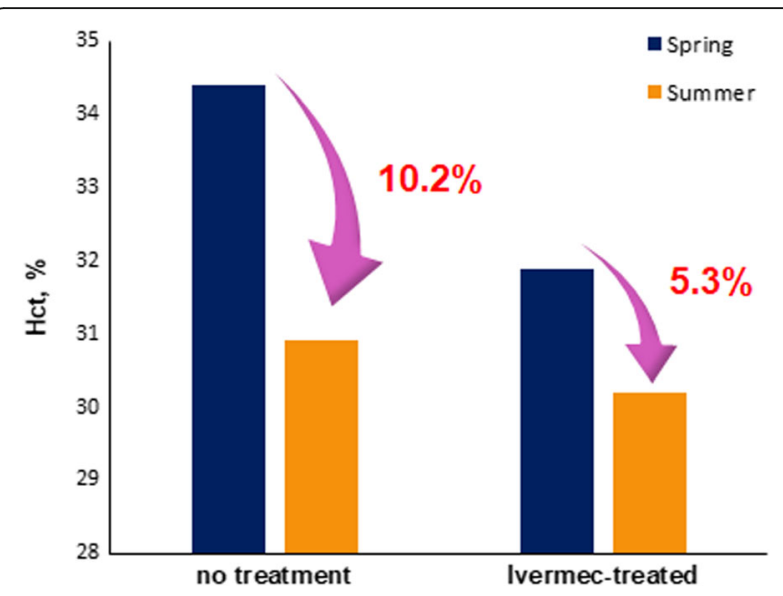

Fig. 3 Differences in blood test results from spring to summer between the control and ivermectin-treated groups. Hematocrit (Hct) value was more reduced in control group than in ivermectin-treated group

\section{Experimental animals}

A cattle farm, located at Jiri Mountain in the ROK, was selected for this study. This farm was well maintained and was consigned by nearby farms to raise Holstein cattle until pregnancy. The cattle were raised on a pasture near the mountain area from spring to autumn. A total of 68 cattle with no prior experience of grazing on this farm were divided into two groups according to treatment with ivermectin (IMEC POUR-ON; ECO Animal Health Ltd., London, United Kingdom); the control group $(n=17)$ was not treated with ivermectin before grazing, whereas the experimental group $(n=51)$ received ivermectin treatment. Ivermectin was poured along the midline in a narrow strip extending from the withers to the tailhead at a dose of $1 \mathrm{~mL}$ ( $5 \mathrm{mg}$ of ivermectin)/10 kg body weight once before grazing (as per the manufacturer's instructions).
Blood collection and hematological examination

Blood $(5 \mathrm{~mL})$ was collected from the jugular veins of 136 cattle (68 cattle during spring [before grazing] and 68 cattle during summer [during grazing]; 17 in the control group and 51 in the experimental group). Each blood sample was stored in EDTA-supplemented tubes at $4^{\circ} \mathrm{C}$ and immediately transported to the laboratory. Hematological examination of the RBC profile ( $\mathrm{RBC}$ count, hemoglobin [Hb] value, hematocrit [Hct] concentration) was performed using an automatic blood analyzer (IDEXX ProCyte Dx; IDEXX Laboratories, Westbrook, ME, USA).

\section{PCR and sequencing}

Genomic DNA was extracted from $200 \mu \mathrm{L}$ of each blood sample using the DNeasy Blood Kit (Qiagen Inc., Valencia, CA, USA), according to the manufacturer's instructions. Tick-borne pathogens including Anaplasma spp., Babesia spp., Ehrlichia spp., Rickettsia spp., and T. orientalis were screened (Table 2) under the following cycling conditions: $95^{\circ} \mathrm{C}$ for $15 \mathrm{~min}$, followed by 40 cycles of $95^{\circ} \mathrm{C}$ for $10 \mathrm{~s}$, $58^{\circ} \mathrm{C}$ for $30 \mathrm{~s}$, and $72{ }^{\circ} \mathrm{C}$ for $30 \mathrm{~s}$, and a final extension at $72{ }^{\circ} \mathrm{C}$ for $5 \mathrm{~min}$. In all experiments, a negative control was included in the PCR assay. The amplicons were run on a $1.5 \%$ agarose gel and visualized following ethidium bromide staining. The PCR products were purified using the AccuPrep ${ }^{\circ}$ PCR Purification Kit (Bioneer, Daejeon, ROK) and directly sequenced (Macrogen, Inc., Seoul, ROK).

\section{Phylogenetic analysis}

DNA sequencing data were analyzed by the Basic Local Alignment Search Tool (BLAST) in the National Center for Biotechnology Information (NCBI) database to determine the homology of $T$. orientalis major piroplasm surface protein (MPSP) genes. The sequences were aligned using ClustalX program. A phylogenetic tree was constructed based on the nucleotide alignments using the neighbor-joining method [29]. Bootstrap analysis was conducted with 1000 replicates using MEGA version 6

Table 2 Primer sequences and PCR conditions used for the detection of tick-borne pathogens in this study

\begin{tabular}{|c|c|c|c|c|c|}
\hline Tick-borne pathogen & Specific genes & Sequence ( $5^{\prime}$ to $\left.3^{\prime}\right)$ & $\begin{array}{l}\text { Annealing } \\
\text { temperature } \\
\left({ }^{\circ} \mathrm{C}\right)\end{array}$ & Amplicon size (bp) & Reference \\
\hline Anaplasma spp. & $16 \mathrm{~S}$ rRNA & $\begin{array}{l}\text { TACCTCTGTGTTGTAGCTAACGC } \\
\text { CTTGCGACATTGCAACCTATTGT }\end{array}$ & 58 & 429 & {$[26]$} \\
\hline Babesia spp. & $18 \mathrm{~S}$ rRNA & $\begin{array}{l}\text { GTTCTGMCCCATCAGCTTGAC } \\
\text { CAAGACAAAAGTCTGCTTGAAAC }\end{array}$ & 61 & $420-440$ & {$[27]$} \\
\hline Ehrlichia spp. & $16 \mathrm{~S}$ rRNA & $\begin{array}{l}\text { CGGAATTCCTAGTGTAGAGG } \\
\text { AGGAGGGATACGACCTTCAT }\end{array}$ & 58 & 340 & {$[26]$} \\
\hline Rickettsia spp. & $16 \mathrm{~S}$ rRNA & $\begin{array}{l}\text { TAGGGGATGATGGAATTCCTA } \\
\text { CCCCCGTCA ATTCCTITGAG }\end{array}$ & 58 & 252 & [26] \\
\hline Theileria orientalis & MPSP* & $\begin{array}{l}\text { CACGCTATGTTGTCCAAGAG } \\
\text { TGTGAGACTCAATGCGCCTA }\end{array}$ & 55 & 830 & {$[28]$} \\
\hline
\end{tabular}


[30]. The 8 sequences obtained in this study were deposited in the GenBank database under the accession numbers MN128425-MN128430 and KY018576- KY018577.

\section{Statistical analysis}

All statistical analyses were performed using the SPSS 24.0 software package (SPSS, Chicago, IL, USA). Hematological results are expressed as the mean \pm standard error of the mean (SEM). Seasonal changes in blood test results were compared between two groups using two-tailed independent $t$-tests depending on the results of normality tests (Shapiro-Wilk test). Differences in the seasonal changes in blood test results between the two groups were also analyzed using two-tailed independent $t$ tests depending on the results of normality tests (ShapiroWilk tests). All graphical procedures were performed using GraphPad Prism 6 for Windows (GraphPad Software Inc., San Diego, CA, USA). Differences with $p$ values of less than 0.05 were considered significant.

\section{Abbreviations}

H. longicornis: Haemaphysalis longicornis; Hb: hemoglobin; Hct: hematocrit; MPSP: major piroplasm surface protein; PCR: polymerase chain reaction; RBC: red blood cell; ROK: Republic of Korea; SEM: standard error of the mean; T. orientalis: Theileria orientalis

\section{Acknowledgements}

We thank Ji-Hyoung Ryu at Department of Animal Science and Biotechnology, Kyungpook National University for the modification of figure.

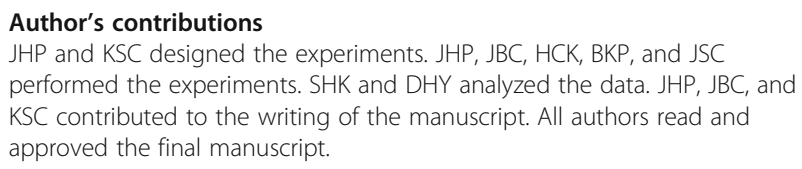
performed the experiments. SHK and DHY analyzed the data. JHP, JBC, and KSC contributed to the writing of the manuscript. All authors read and approved the final manuscript.

\section{Funding}

This work was supported by the Ministry of Education of the Republic of Korea and the National Research Foundation of Korea (NRF-

2017R1A2B2005685). This research was partially supported by Technology Development Program (Project No. 1116043-1) for Bio-industry, Ministry for Agriculture, Food and Rural Affairs, Republic of Korea. The funders had no role in the study design, data collection and analysis, interpretation of results, writing of the report, decision to submit the paper for publication.

\section{Availability of data and materials}

All data generated or analyzed during this study are included in the article.

\section{Ethics approval and consent to participate}

All procedures involving animals in this study were performed in accordance with the ethical standards of the Chonbuk National University Animal Care and Use Committee (CBU 2016-00026). We obtained written informed consent from the owner of the animals for using them in our study.

\section{Consent for publication}

Not applicable.

\section{Competing interests}

The authors declare that they have no competing interests.

\section{Author details}

'College of Veterinary Medicine, Chonbuk National University, Iksan 54596, South Korea. '2aboratory of Veterinary Internal Medicine, BK21 PLUS Program for Creative Veterinary Science Research, Research Institute for Veterinary Science and College of Veterinary Medicine, Seoul National University, Seoul
08826, South Korea. ${ }^{3}$ Gyeongsang National University Hospital, Jinju 52727, South Korea. ${ }^{4}$ Institute of Animal Medicine, College of Veterinary Medicine, Gyeongsang National University, Jinju 52828, South Korea. ${ }^{5}$ College of Veterinary Medicine, Kangwon National University, Chuncheon 24341, South Korea. ${ }^{6}$ College of Veterinary Medicine, Chungnam National University, Daejeon 34134, South Korea. ${ }^{7}$ College of Ecology and Environmental Science, Kyungpook National University, Sangju 37224, South Korea.

Received: 2 February 2019 Accepted: 5 August 2019

Published online: 17 August 2019

\section{References}

1. McFadden AM, Rawdon TG, Meyer J, Makin J, Morley CM, Clough RR, Tham K, Mullner P, Geysen D. An outbreak of haemolytic anaemia associated with infection of Theileria orientalis in naive cattle. N Z Vet J. 2011;59:79-85.

2. Perera PK, Gasser RB, Firestone SM, Anderson GA, Malmo J, Davis G, Beggs DS, Jabbar A. Oriental theileriosis in dairy cows causes a significant milk production loss. Parasit Vectors. 2014;7:73.

3. Perera PK, Gasser RB, Pulford DJ, Stevenson MA, Firestone SM, McFadden AM, Jabbar A. Comparison of the performance of three PCR assays for the detection and differentiation of Theileria orientalis genotypes. Parasit Vectors. 2015;8:192.

4. Riek RF. Epidemiology and transmission of Theileria sp of cattle in Australia. Aust Vet J. 1982;59:89-92.

5. Chong ST, Kim HC, Lee IY, Kollars TM Jr, Sancho AR, Sames WJ, Chae JS, Klein TA. Seasonal distribution of ticks in four habitats near the demilitarized zone, Gyeonggi-do (province), Republic of Korea. Korean J Parasitol. 2013;51:319-25.

6. Heath A. Biology, ecology and distribution of the tick, Haemaphysalis longicornis Neumann (Acari: Ixodidae) in New Zealand. N Z Vet J. 2016;64:10-20.

7. Jenkins C, Micallef M, Alex SM, Collins D, Djordjevic SP, Bogema DR. Temporal dynamics and subpopulation analysis of Theileria orientalis genotypes in cattle. Infect Genet Evol. 2015;32:199-207.

8. Mekata H, Minamino T, Mikurino Y, Yamamoto M, Yoshida A, Nonaka N, Horii Y. Evaluation of the natural vertical transmission of Theileria orientalis. Vet Parasitol. 2018:263:1-4.

9. Perera PK, Gasser RB, Anderson GA, Jeffers M, Bell CM, Jabbar A. Epidemiological survey following oriental theileriosis outbreaks in Victoria, Australia, on selected cattle farms. Vet Parasitol. 2013;197:509-21.

10. Park J, Han YJ, Han DG, Chae JB, Chae JS, Yu DH, Lee YS, Park BK, Kim HC, Choi KS. Genetic characterization of Theileria orientalis from cattle in the Republic of Korea. Parasitol Res. 2017;116:449-54.

11. d'Alexis S, Periacarpin F, Jackson F, Boval M. Mixed grazing systems of goats with cattle in tropical conditions: an alternative to improving animal production in the pasture. Animal. 2014;8:1282-9.

12. Barkema HW, von Keyserlingk MA, Kastelic JP, Lam TJ, Luby C, Roy JP, LeBlanc SJ, Keefe GP, Kelton DF. Invited review: changes in the dairy industry affecting dairy cattle health and welfare. J Dairy Sci. 2015;98:7426-45.

13. Choi KS, Yu DH, Chae JS, Park BK, Yoo JG, Park J. Seasonal changes in hemograms and Theileria orientalis infection rates among Holstein cattle pastured in the mountains in the Republic of Korea. Prev Vet Med. 2016;127:77-83.

14. Miller JA, Davey RB, Oehler DD, Pound JM, George JE, Ahrens EH. Control of Boophilus annulatus (Acari: Ixodidae) on cattle using injectable microspheres containing ivermectin. J Econ Entomol. 1999;92:1142-6.

15. de la Fuente J, Almazan C, Canales M, Perez de la Lastra JM, Kocan KM. Willadsen P. a ten-year review of commercial vaccine performance for control of tick infestations on cattle. Anim Health Res Rev. 2007:8:23-8.

16. Yamane I, Arai S, Nakamura Y, Hisashi M, Fukazawa Y, Onuki T. A clinical trial to evaluate the effects of flumethrin or ivermectin treatment on hemoparasites, gastrointestinal parasites, conception and daily weight gain in a dairy farm in Japan. Prev Vet Med. 2000;43:203-10.

17. Pereira JR. The efficiency of avermectins (abamectin, doramectin and ivermectin) in the control of Boophilus microplus, in artificially infested bovines kept in field conditions. Vet Parasitol. 2009;162:116-9.

18. Davey RB, Miller JA, George JE, Miller RJ. Therapeutic and persistent efficacy of a single injection treatment of ivermectin and moxidectin against Boophilus microplus (Acari: Ixodidae) on infested cattle. Exp Appl Acarol. 2005;35:117-29.

19. Lunke MD, Kaufman WR. Effects of the avermectin analogue MK-243 on vitellogenesis and reproduction in the ixodid tick, Amblyomma hebraeum. Exp Appl Acarol. 1992;13:249-59. 
20. El-Bahy NM, Bazh EK, Shaheen HM. Efficacy of deltamethrin, diazinon, and ivermectin on Boophilus annulatus ticks (in vitro and in vivo study). Parasitol Res. 2015;114:29-36.

21. Rodriguez-Vivas RI, Ojeda-Chi MM, Trinidad-Martinez I, Perez de Leon AA. First documentation of ivermectin resistance in Rhipicephalus sanguineus sensu lato (Acari: Ixodidae). Vet Parasitol. 2017;233:9-13.

22. Campbell WC, Fisher MH, Stapley EO, Albers-Schonberg G, Jacob TA. Ivermectin: a potent new antiparasitic agent. Science. 1983;221:823-8.

23. Yacob HT, Mistre C, Adem AH, Basu AK. Parasitological and clinical responses of lambs experimentally infected with Haemonchus contortus (L3) with and without ivermectin treatment. Vet Parasitol. 2009;166:119-23.

24. Hammer JF, Emery D, Bogema DR, Jenkins C. Detection of Theileria orientalis genotypes in Haemaphysalis longicornis ticks from southern Australia. Parasit Vectors. 2015;8:229.

25. Campbell WC. Lessons from the history of Ivermectin and other Antiparasitic agents. Annu Rev Anim Biosci. 2016;4:1-14.

26. Saitou N, Nei M. The neighbor-joining method: a new method for reconstructing phylogenetic trees. Mol Biol Evol. 1987;4:406-25.

27. Kumar S, Stecher G, Tamura K. MEGA7: molecular evolutionary genetics analysis version 7.0 for bigger datasets. Mol Biol Evol. 2016;33:1870-4.

28. Seong G, Han YJ, Oh SS, Chae JS, Yu DH, Park J, Park BK, Yoo JG, Choi KS. Detection of tick-borne pathogens in the Korean water deer (Hydropotes inermis argyropus) from Jeonbuk Province, Korea. Korean J Parasitol. 2015;53: 653-9.

29. Hilpertshauser H, Deplazes P, Schnyder M, Gern L, Mathis A. Babesia spp. identified by PCR in ticks collected from domestic and wild ruminants in southern Switzerland. Appl Environ Microbiol. 2006;72:6503-7.

30. Kakuda T, Kubota S, Sugimoto C, Baek BK, Yin H, Onuma M. Analysis of immunodominant piroplasm surface protein genes of benign Theileria parasites distributed in China and Korea by allele-specific polymerase chain reaction. J Vet Med Sci. 1998;60:237-9.

\section{Publisher's Note}

Springer Nature remains neutral with regard to jurisdictional claims in published maps and institutional affiliations.

Ready to submit your research? Choose BMC and benefit from:

- fast, convenient online submission

- thorough peer review by experienced researchers in your field

- rapid publication on acceptance

- support for research data, including large and complex data types

- gold Open Access which fosters wider collaboration and increased citations

- maximum visibility for your research: over $100 \mathrm{M}$ website views per year

At $\mathrm{BMC}$, research is always in progress.

Learn more biomedcentral.com/submissions 